\title{
Paideusis
}

\section{Liberal Values, Group Rights, and Multicultural Education}

\section{Basil R. Singh}

Volume 12, Number 1, 1998

URI: https://id.erudit.org/iderudit/1073095ar

DOI: https://doi.org/10.7202/1073095ar

See table of contents

Publisher(s)

Canadian Philosophy of Education Society

ISSN

0838-4517 (print)

1916-0348 (digital)

Explore this journal

Cite this article

Singh, B. (1998). Liberal Values, Group Rights, and Multicultural Education.

Paideusis, 12(1), 37-47. https://doi.org/10.7202/1073095ar

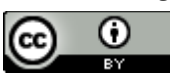

This document is protected by copyright law. Use of the services of Erudit (including reproduction) is subject to its terms and conditions, which can be viewed online.

https://apropos.erudit.org/en/users/policy-on-use/
This article is disseminated and preserved by Érudit.

Érudit is a non-profit inter-university consortium of the Université de Montréal, Université Laval, and the Université du Québec à Montréal. Its mission is to promote and disseminate research.

https://www.erudit.org/en/ 


\section{Liberal Values, Group Rights, and Multicultural Education}

Basil R. Singh, University of Sunderland

\section{Introduction}

This paper discusses the implications of liberalism for multicultural education and for a cultural pluralist society. ${ }^{1}$ It argues that if individuals are, in part, constituted by their culture-that is, if the self is embedded in culture, then a liberal education system must account for this fact when it sets out to educate. Among other things, education must be concerned, especially at the moral level, with respect for persons. Culture is seen here as a primary good, basic to what people can identify with as part of a good life.

While some people may identify with more than one culture in a pluralistic society, the majority may identify with only one. Where core values of different cultures differ, cultural conflicts, especially at an institutional level, may arise. This paper examines procedures for minimising the adverse effects of cultural or value conflicts and offers some suggestions for achieving consensus without a loss of dignity. The limitation of discussion as a means of resolving moral or value conflicts is recognised. The paper also recognises the inherent conflict between the liberal demands for personal autonomy and the demands of ethnic minorities for group rights. The paper explores the controversy surrounding this area and concludes that each must be taken into account when we set out to formulate policies for a pluralist democratic society.

Liberalism holds that, given the controversial nature of morals, there can be no comprehensive account of the good life for humans which should be imposed on all citizens of a pluralist society or invoked to characterise and underpin the notion of public good. ${ }^{2}$ What is needed according to liberals is a conception of the good, free of significantly controversial assumptions, which maximises the freedom of citizens to pursue their diverse private conceptions of the good within a framework of justice. On this account, the state must be neutral on matters of private good. It has a non-neutral commitment to the basic principles of justice involved in the notion of the good in public terms and, on this basis, seeks to achieve a balance between cohesiveness and diversity. ${ }^{3}$

Liberalism requires neutrality with regard to ideas of the good life but, as Feinberg argues, it does not require ignorance with regard to different conceptions of the good life. In this sense, liberalism is no enemy to multicultural education. Questions of balance and proportion may well be raised, but there is little in liberal theory itself that would lead one to reject learning about other cultures. $^{4}$ Rejecting a person's culture could be tantamount to rejecting the person himself or herself. Indeed, self-recognition comes partly from the recognition of others and this self-recognition cannot be obtained where the core values of a person's culture are excluded from the curriculum. The granting of this view, therefore, would require a massive change in the national curriculum, for reasons indicated by Taylor ${ }^{5}$ who argues that the reason for changing the curriculum: 
is not or not mainly that all students may be missing something important through the exclusion of a certain gender or certain races or cultures, but rather that women and students from excluded groups are given, either directly or by omission, a demeaning picture of themselves, as though all creativity and worth inhered in males of European provenance. Enlarging and changing the curriculum is, therefore, essential not so much in the name of broader culture for everyone as in order to give recognition to the hitherto excluded. ${ }^{6}$

According to Taylor, enlarging the curriculum to take the perspective of other (minority) culture into account would facilitate the equal recognition for all groups including the majority and minority groups. The presumption of equal worth should "give us reason to search the world over, with patience and with care, to find and learn to appreciate great human achievements, wherever they may be."7 The presumption here is that there "is a need for a conscientious recognition of cultural diversity ... . we may even say that justice requires it." 8 If individuals are, at least in part, constituted by their cultural identities, as Taylor argues, then it will follow that a liberal state is charged with providing the basic conditions for citizen self-determination and with protecting and promoting the legitimate self-defining activities of the group through which its citizens structure their identities.

\section{Culture, Identity and Choice}

Culture provides the context of individual choice. It provides a context that gives meaning and guidance to individual choice in life. It is because the self itself is embedded in culture that Gutmann argues that a secure cultural context ranks among the primary goods basic to most people's prospects for living what they can identify as a good life. 9

Walzer, ${ }^{10}$ too, maintains that membership in communities is an important good and that the primary subjects of values are particular historical communities and what is most important is that there is nothing more to correctness of values for a particular community than those values that are now embraced by that community. As to what determines justice in such a community, Walzer writes: ". . . the choices we have already made in the course of our common life ... (and) understandings ... we (really) share."11 A society is just if and only if it is faithful to its traditional values. As Walzer puts it: " . . . if its substantive life is lived ... in a certain way faithful to the shared understandings of the members, then justice requires that the society be faithful to the disagreements, providing institutional channels for their expressions." 12 MacIntyre, ${ }^{13}$ also, sees the self as embedded in culture:

... we all approach our own circumstances as bearers of a particular social identity .... Hence what is good for me has to be the good for one who inhabits these roles. As such, I inherit from the past of my family, my city, my tribe, my nation, a variety of debts, inheritances, rightful expectations and obligations. These constitute the given of my life, the moral starting point. This is in part what gives my life its own moral particularity. ${ }^{14}$

MacIntyre does not think that the "self [can be] detached from its social and historical roles and statuses," but he accepts that "rebellion against my identity is always one possible mode of expressing it." 


\section{Culture and Equality}

Although it is undeniable that the self is embedded in culture, it does not follow that every self is embedded in only one culture or that every culture offers all its members equality of opportunity or equal respect. In fact, throughout its history western and (non-western) societies alike excluded women and minorities and repressed most significant deviations from the dominant norm in the name of the common good. Most of these societies had settled roots and established traditions that did not tolerate deviation from those norms. As Gutmann argues: "A great deal of intolerance has come from societies of selves so 'confidently situated' that they were sure repression would serve a higher cause."15 What is required to counter such dangers, as Gutmann sees it, is an "enforcement of liberal rights, not the absence of settled community: the enforcement of these rights stands between the Moral Majority and the contemporary equivalent of witch-hunting."16

If members are to act in conformity to the requirements of the community (which may experience disagreement and conflict), how would they be able to challenge the institutional framework, if sharing in that social normative framework is tantamount to conforming to its norms? If shared values exist in an ongoing way of life and in institutionalised social action, then sharing in those values and thereby conforming to them, would be equivalent to supporting that way of life, even if it means harming one's own interests. Surely justice does not require that we support social norms that are obviously contrary to our interests, equity, dignity, development, or freedom. It is precisely because of these problems associated with some communities and groups that some people support liberalism.

Liberalism, especially of the Rawlsian type, ${ }^{17}$ gives pride of place to justice, fairness, and individual rights. Its core thesis is that a just society seeks not to promote any particular ends, but enables its citizens to pursue their own ends, consistent with a similar liberty for all. The liberal state must govern by principles that do not presuppose any conception of the good life. In such a liberal state, citizens can pursue their own values and ends consistent with a similar liberty for others. Sandel sums up the liberal vision as "the right is prior to the good" which means that "individual rights cannot be sacrificed for the sake of the general good ... [and] the principles of justice that specify these rights, cannot be premised on any particular vision of the good life."18

Liberals such as Rawls argue that to restrict an individual's exercise of the freedom of conscience is to violate an individual's fundamental human right. Thus, Rawls seems to equate the principle of toleration with the idea of individual freedom of conscience. While liberals would go along with the communitarian view that our shared ends are to be found in our historical practices and roles we occupy, they draw attention to the fact that:

... those roles and practices were defined by a small portion of the society-propertied, white men, to serve the interests of propertied white men. These practices remained gender-coded, race-coded, class-ooded, even when women, blacks and workers are legally allowed to participate in them. ${ }^{19}$

Thus, liberals argue that such communal shared ends only serve to legitimate, exclude, and alienate marginalised individuals or groups in society, 20 
and that the historical group or community view of the common good has resulted in the exclusion of many individuals in society. Hirsch notes:

... any 'renewal' or strengthening of community sentiment will accomplish nothing for these groups. On the contrary, our historical sentiment and traditions are 'part of the problem,' not part of the solution. ${ }^{21}$

The liberal position of granting communities rights or granting rights to groups will not be enough to ensure respect for persons or individual autonomy unless individuals within a group are treated as equals-equals in terms of defining their roles, identities, practices, and ends-and allowed to shape institutions that will serve those ends.

Liberals accept that communities are the source of individual cultural identity but emphasize communities rather than community. Although liberals may go along with the view that individual cultural life is embedded in particular communal relations with shared meanings of social goods, they point out that, while communities can be sources of individual flourishing, they can also cripple the development of sections of their people who historically may be seen as deserving less respect, less dignity, and unequal treatment.

Hence, for liberals "self-discovery," "coming to an awareness," "acknowledging one's attachment to one's community" cannot be enough if such attachments forecloses judgements about how to lead one's life. ${ }^{22}$ We do find ourselves in various roles and relationships in a community, but we may not like what we find. The roles and relationships may be oppressive or demeaning, and may be experienced as suffocating rather than embracing. It is for these reasons that some liberals insist that:

No matter how deeply implicated we find ourselves in a social practice or tradition, we [should] feel capable of questioning whether the practice is a valuable one. ${ }^{23}$

As we noted, liberals seem to point to two pre-conditions for the fulfilment of our essential interest in leading a life that is good:

One is that we lead our life from the inside, in accordance with our beliefs about what gives value to life, the other is that we are free to question those beliefs, to examine them in the light of whatever information and examples and arguments our culture can provide. ${ }^{24}$

But how important would such liberal principles be for authenticity and revisability for traditional based or tradition-bound groups? While a liberal may have little confidence in her current beliefs about the good life and may wish to constantly revise them, a member of a highly stable tradition-bound society may be quite confident in her beliefs and, as McDonald ${ }^{25}$ points out, she may on reflection think it is a waste of time and energy to revise or reject received notions of the good life or projects. In his words:

Why would we expect for all societies and all cultures that the political conditions appropriate to fostering the fundamental re-examination of values should be regarded as an indispensable part of leading the best possible life. ${ }^{26}$

Indeed, why would one want to question or revise one's religious beliefs which provide a comprehensive framework for one's life and shape one's fundamental choices? One might even think that such revision would be contrary to one's 
religious values and thereby be anxiety-producing and socially destabilising. All this suggests, according to McDonald,

... that there is no single, uniform, cross-culturally valid, prudential rationale for taking revisability as a premier desideratum for personal and political life. Indeed, it suggests that cultural context may have a great deal to do with the appropriate prudential response to the liberal programme. ${ }^{27}$

A liberal state must recognise the value of pluralism in all its forms and that many different life forms are, although incompatible, valuable at least to their own members. This is to suggest that we should "reject the belief in the reducibility of all values to one value that serves as a common denominator to all the valuable ways of life."28

Respecting value pluralism could mean a rejection of a reductive-monistic valuable form of life. Accepting value pluralism may mean learning to live with the inescapable tension and rivalry between competing valuable ways of life where incompatible options coexist in the same society. ${ }^{29}$ Such tensions, rivalry, and incompatibilities require that each community should be tolerant of others if they wish to live in harmony.

Liberal society is under an obligation to allow the existence of cultural groups and respect their identity on the basis of freedom and human dignity. These considerations call upon governments to take action that goes beyond that required by policies of toleration and non-discrimination. In pursuing these ends, liberalism must transcend an individualistic approach and recognise the importance of membership in a respected and flourishing cultural group for individual well-being. ${ }^{30}$ Perhaps, as Raz recommends, "[W]e should learn to think of our societies as consisting not of a majority and minorities, but of a plurality of cultural groups",31 and perhaps, one may add, a plurality of cultural options available to all.

A liberal view that allows cultural diversity also increases the range of available options which encourages a healthy competition between different ways of life and deepens our knowledge of the nature and possibilities of human existence. ${ }^{32}$ Since this is so, according to Parekh:

... the liberal cannot consistently privilege the liberal way of life and conduct an assimilationist campaign against ways of life and thought that differ from his [sic] own. For to do so is to assume that the liberal way of life alone is 'true' and represents the last word in human wisdom. ${ }^{33}$

Because of the inherent conflict between liberalism and some traditional cultural beliefs, and in the dilemma inherent in autonomy-based liberalism, it is impossible to achieve agreement on all levels either politically or educationally across all cultural groups within society. Tamir contends that "the most that can be achieved is an untidy compromise which all parties resent to some extent."34 Solutions to problems arising from conflicts between liberalism and some traditional cultural beliefs, Tamir adds, cannot be defined as a priori but must be the product of constant political discussion and negotiation. But what form should these take? What principles, especially at the classroom level, should govern the procedure or process so that the equal dignity of individuals is preserved? 


\section{Discussion as a Method of Resolving Value Conflict}

Classroom discussion should equip pupils now and later in life to answer moral or value questions for themselves. For such discussions to succeed, however, they will, according to Hare, have to proceed in accordance with certain methodological principles or rules and the substantive views or values that the participants may come to hold about the questions at issue. ${ }^{35}$ People may disagree on these important substantive questions, but, as Hare puts it, they,

may yet agree about the methodology and the logic, and the best way to help children to answer the substantive questions is to teach them a method of arguing fairly, clearly and logically about them. ${ }^{36}$

According to Hare, in such discussions, disputants would be expected to understand the question that they are disputing, the evidence adduced in support of assertions, and the views of others. Thus, although individuals could reach their own decisions about values, the method for reaching and discussing them would be determined by certain procedures and the nature of the subject matter. It is not assumed, however, that procedures and clarification of terns and the examination of evidence will determine the conclusions. People may differ for all sorts of reasons based on their culture, religion, world-views or interests.

However, if our purpose is to work toward achieving an objective moral compromise or consensus, then participants must abide by certain rules and procedures. For example, every participant in a discussion or dialogical inquiry must take into account the perspective of the other participants: each must follow the rules of argument, coherence, consistency, and validity. Being able to enter into legitimate moral dialogue may, in fact, presuppose a deliberate adherence to the imperative to 'respect for persons.' A moral judgement evolving from such a dialogue--that is, from a collaborative endeavour-would be justified if it generates agreement by everyone who is party to the decision-making group. This process will require, according to Kohlberg, "equal consideration of the claim or points of view of each person affected by the moral decision., 37

It is to be admitted, however, that although discussion has its value in attempting to find a compromise in value conflict, it can take us only so far in ethical disagreement. Both parties to the discussion could argue from their customary practices and value stances and hold that their preferred beliefs are true and are based on rational grounds. Each could point out that there is no recognisable standard of reasoning by which they can be shown to be absolutely false or incorrect. Both parties could justify beliefs on cultural grounds and could accept that their arguments, as everyone else's, are culturally bound. It is for this reason that Macintyre sees this as our major moral predicament which lies in our attempt to "... use moral speech to assert emotive preferences, through cloaking our preferences behind the veneer or moral principles thought to provide objective foundations and grounding." 38

Hence, for MacIntyre, dialogue on moral matters could be little more than the assertion of moral principles whose premises are incommensurable. It is just this incommensurability that contributes to the interminability of moral debate. If social harmony is our goal and if it is to be maintained through certain institutions, we need to negotiate our way through the impasse of conflict, and one may add, through some collaborative endeavour, and following the procedures already referred to by Hare. 
In such a collaborative endeavour and in a free society, each person's moral views would be submitted to the marketplace of ideas in group discussion. Thus, in engaging in discussion, one hopes to increase the likelihood that just solutions will be found for hard-case dilemmas, solutions that will encourage agreement because of their evident rationality and fairness. The whole process of dialogical inquiry and communication will, therefore, proceed in the hope of finding stable or tentative solutions. ${ }^{39}$ Active attempts should be made to understand the points of view of others and to co-ordinate this understanding with one's own reasons in such a way that disputants will be encouraged to yield to convincing arguments. Dialogue of this sort would be grounded by a number of presuppositions including among them equality, mutual respect, freedom from coercion, and rationality. ${ }^{40}$ Participants would be expected to strive to give moral discussion a chance to succeed.

Such discussion or communication would require some equality of position for the purpose of putting forward solutions and participating in their discursive redemption. In such a dialogical, communicative atmosphere, no one will assume a privileged position by virtue of his or her religion, culture, race or ethnicity. The aim would be seen in terms of a search "for the best means of regulating overlapping and competing needs and interests for the purpose of a mutual redemption of ... [the] validity [of their claims]." 41

What warrants those claims as better or worse can be found only through the quality of the dialogic activity among all concerned. The aim of such a dialogical inquiry would be to bring about a commitment among members to "talk through our cultural diversity about how we should make sense of it together... also for the next generation to talk to us and to each other in the continual activity of making this sense." 42 This requires that we keep an openmind, not just for our own sake, but also for those to come. If the question as to what constitutes the good life for all members of a cultural pluralist society is to be kept open, then it must follow that no static truth claims about morals will be given a privileged position. All claims will be looked upon as means of regulating overlapping and competing needs and interests. It is the quality of the dialogue that could determine the aim or path to be chosen, the decision to be made, the compromise that is to be reached for social harmony, and social or moral progress. Dialogical inquiry is, thus, directly related to a policy of compromise or tolerance and non-violent persuasion ${ }^{43}$ for, ultimately, social harmony may well depend on it.

The assumption for tolerance and compromise and non-violent persuasion is based on the observation that in a pluralist society moral disagreements will arise. Rawls, for instance, sees moral diversity and disagreements because

$\ldots$ the diversity of comprehensive religious, philosophical and moral doctrines found in modern democratic societies is not a mere historical condition that may soon pass away; it is a permanent feature of the public culture of democracy. ${ }^{44}$

Indeed, the political and social conditions under a democracy, that allows basic rights and liberties to exist, also allows diversity of conflicting and irreconciling comprehensive doctrines to emerge. These "will persist and may increase." For, as Rawls writes: " . . a diversity of comprehensive doctrines is a permanent feature of a society with free institutions ...."45 
Consequently, we should recognise that with all our goodwill, "reasonable disagreements on matters of the first significance" may still remain or "that agreement ... may not be attainable in the present case, [or] at least in the foreseeable future." 46 Realising this, people should enter discussion ready to credit others with certain good faith and "expect deep differences of opinion and accept .... diversity as the normal state of public culture of a democratic society." These facts, as Rawls notes, "are rooted in the difficulties of exercising our reason under the normal conditions of human life." 47

\section{Conclusion}

If understanding ourselves is an aim of education, then understanding our cultural heritage, becomes an important part of education. If other cultures are part of our cultural heritage, then it would make sense to understand other cultures as well. What to include in the curriculum when we set out to educate from a multicultural perspective remains problematic, but not impossible to work out in theory, if not in practice. Perhaps, as Taylor indicates, a comparative study of the worth of various cultures may help us to evaluate the validity of each culture and to deepen our understanding of what is worthy of inclusion in a multicultural curriculum. It may help us to achieve what Taylor refers to as a "fusion of horizons" 48 In this process, "we learn to move in a broader horizon within which what we have formerly taken for granted as the background to valuation can be situated as one possibility alongside the different background of the formerly unfamiliar culture." 49 The "fusion of horizon" will come about, according to Taylor, "through our developing new vocabularies of comparison, by means of which we can articulate these contrasts." 50 In a multicultural education setting, we ought to learn "how to listen and how to discourse about our differences where the rules of discourse-both our own and other's rules-are part of what we are listening for." 51 In such discourse, we may come to understand other people's understanding of their and our culture. We come to learn through the perspectives and categories provided by another culture. In our discourse, we should bear in mind of the risk of one group dominating the other and abide by the ethical and procedural rules. We should also be aware of the limitations of procedures for discussion. As Gutmann reminds us, discourse and "procedures alone cannot carry the complete moral load that ... relativism requires." 52 Our endeavour should, therefore, be seen as a search for shared social understandings and just procedures that are more likely to result in justice for all concerned. Searching for shared understanding does not mean that we shall find it. When moral conflicts arise from people holding different world views marked by incompatibilities of perception and belief over good and evil or over the good life, these conflicts are not removed by appealing to rationality (whatever that might mean to different groups in the dispute) or to rational procedures, or to some common ground which the adversaries share or by appealing to some higher moral tribunal capable of an intersubjective adjudication of controversies. Thus, although dialogue will not resolve all moral disagreement, it could provide deep insight of the reasons why different groups hold different positions. It will deepen our understanding of each other and perhaps makes us more tolerant of each other's views. 
Although the truth of a community's belief cannot be entirely left up to them, it does not follow that a community cannot in certain circumstances and in many spheres of social or moral life decide what is of value to it. Moreover, it would be rash to presume that there is only one correct answer to every value question. As Crittenden argues, "where moral conflicts arise there may be more than one rationally defensible moral decision....",53

These conflicts, as we argued earlier, may not be subject to easy rational solutions. However, one must not be too pessimistic, for there are people who are struggling to find a solution. Kymlicka ${ }^{54}$ attempts to reconcile the conflict between individual and community rights. He argues that liberalism does not necessarily undermine the good of the community as communitarians fear. On the other hand, he argues that some liberals have in the past overlooked the importance cultural membership plays in individual well-being. Consequently, liberals need to reflect more carefully on what it is to belong to a cultural community. Members of a cultural community do have deep abiding interests in their community which they see as a primary good.

While communitarians are correct in drawing our attention to the role of community in influencing our lives, liberals are right to emphasise the protection of individual liberties especially for those members who may feel oppressed by their communities and would wish to assert their rights without being penalty. For Kymlicka, there are:

... two preconditions for the fulfilment of our essential interests in leading a life that is good. One is that, we lead our life from the inside, in accordance with our beliefs about what gives value to life; the other is that, we should be free to question those beliefs, to examine them in the light of whatever information and examples and arguments our culture can provide. ${ }^{55}$

Although one may accept that "no life goes better by being led from the outside according to values the person does not endorse," 56 what if an individual, after some reflection, accepts being by its community-from the outside? Surely, liberalism allows for individuals to pursue their interests, especially if these interests do not harm others. Liberalism must allow for the fact that some people may not see liberalism as the best means of effectively promoting their well-being and, as Lenihan points out, "there is a serious question about what it means either to have your life 'led from the outside' or to 'endorse' values." 57 He adds that endorsing certain community values may involve assenting to the kinds of actions they imply for the members of this community and to do so is to certainly endorse its values. 58

What Kymlicka and others are trying to do is to situate the self and still preserve autonomy which both communitarians and liberals are not so far able to do. According to Lenihan, the real issue facing us is:

how far away from rationalist conceptions of the self can we go before the notion of autonomy disappears altogether? How particularised can we make the self before the will dissolves in a welter of social forces? ${ }^{59}$

For Lenihan, we cannot give the self over to history-its history-in which it could be overwhelmed by the forces of history, nor can we detach the autonomous self from its Kantian rationalist foundations before leaving it naked before the elements. The solution, he suggests, might be to retain the rights of the individual to act in accordance with his or her self-imposed rational, justified 
standards of morality and also retain the rights of groups to protect their cultural identity within a framework of human rights.

\section{Notes}

${ }^{1}$ Liberalism is seen here as a political theory of limited government which provides institutional guarantees for personal liberty.

${ }^{2}$ T.H. McLaughlin, "Liberalism, Education and the Common Classroom," Journal of the Philosophy of Education, 29(2), 1995, 240.

${ }^{3}$ Ibid.

${ }^{4} \mathrm{~W}$. Feinberg, "Liberalism and the Aims of Multicultural Education," Journal of Philosophy of Education, 29(2), 1995, 203-216.

${ }^{5} \mathrm{C}$. Taylor, Philosophical Papers. Vol. 2: Philosophy and the Human Sciences (Cambridge: Cambridge University Press, 1985).

${ }^{6} \mathrm{C}$. Taylor, "The Politics of Recognition." In A. Gutmann (Ed.), Multiculturalism and the Politics of Recognition (Princeton, NJ: Princeton University Press, 1992), 65-66.

${ }^{7}$ S. Wolf (1992), "Comment." In A. Gutmann (Ed.), op. cit., 84.

${ }^{8}$ Ibid.

${ }^{9}$ Ibid., 3-24.

${ }_{10} \mathrm{M}$. Walzer, Spheres of Justice. A Defence of Pluralism and Equality (Oxford: Blackwell, 1983).

${ }^{11}$ Ibid., 5.

12 Ibid., 313.

${ }^{13}$ A. MacIntrye, After Virtue: A Study in Moral Theory (London: Duckworth, 1982).

${ }^{14}$ Ibid., 204-205.

${ }^{15}$ A. Gutmann, "Communitarian Critics of Liberalism," Philosophy and Public Affairs, 14, 1985, 319.

${ }^{16}$ Ibid.

${ }^{17} \mathrm{~J}$. Rawls, Theory of Justice (Cambridge, MA: Harvard University Press, 1971) and "The Idea of an Overlapping Consensus," Oxford Journal of Legal Studies, 7(1), 1987.

${ }_{18} \mathrm{M}$. Sandel, "The Procedural Republic and the Unencumbered Self," Political Theory, 12, 1984, 82.

${ }^{19}$ W. Kymlicka, Liberalism, Community and Culture (Oxford: Clarendon Press, 1989).

${ }^{20}$ See A. Gutmann, op. cit., 318-324.

${ }^{21} \mathrm{H}$. Hirsch, "The Theory of Liberalism: Constitutional Liberty and the Renewal of Community," Political Theory, 14(3), 1986, 424.

${ }^{22}$ Kymlicka, op. cit., 53.

23 Ibid.

${ }^{24}$ Ibid.

${ }^{25}$ M. McDonald, "Should Communities Have Rights? Reflections on Liberal Individualism," Canadian Journal of Law and Jurisprudence, 4(2), 1991, 217-237.

${ }^{26}$ Ibid., 217.
${ }^{27}$ Ibid. 
${ }^{28}$ J. Raz, "Multiculturalism: A Liberal Perspective," Dissent, (Winter)

29 Ibid., 73.

${ }^{30}$ Ibid.

${ }^{31}$ Ibid., 78.

${ }^{32}$ B. Parekh, "Decolonizing Liberalism," in Aleksandras Shtromas (Ed.), The End of Isms? Reflections on the Fate of Ideological Politics After Communism's Collapse (Oxford: Blackwell, 1994), 85-103.

${ }^{33}$ Ibid., 102.

${ }^{34}$ Y. Tamir, "Two Concepts of Multiculturalism," Journal of Philosophy of Education, 29(2), 1995, 171.

${ }^{35}$ R.M. Hare, "Value Education in a Pluralist Society," Proceedings of the Philosophy of Education of Great Britain, 10, (July) 1976, 7-23.

${ }^{36}$ Ibid., 13.

${ }^{37} \mathrm{~L}$. Kohlberg, "A Current Statement on Some Theoretical Issues," in L. Kohlberg, Consensus and Controversy (Philadelphia, PA: Falmer Press, 1986).

${ }^{38}$ MacIntyre, 1982, op. cit., 62.

${ }^{39}$ D.K. Lapsley, "Pluralism, Virtues and the Post-Kohlbergian Era in Moral Psychology," in F.C. Power and D.K. Lapsley (Eds.), Education, Politics, and Virtues: The Challenge of Pluralism (Notre Dame, IN: The University of Notre Dame Press, 1992), 172.

${ }^{40}$ Ibid.

${ }^{41}$ D. Boyd, "The Moral Part of Pluralism as the Plural Part of a Moral Education," in F.C. Power and D.K. Lapsley (Eds.), op. cit., 159.

42 Ibid., 158.

${ }^{43}$ B. Crittenden, Cultural Pluralism and Common Curriculum (Melbourne: Melbourne University Press, 1982).

${ }^{44}$ J. Rawls, "The Domain of the Political and Overlapping Consensus," New York University Law Review, 64(2), 1989, 234.

45 Ibid., 235.

${ }^{46}$ Ibid., 238.

${ }^{47}$ Ibid., 239.

${ }^{48}$ Taylor, op. cit., 67.

49 Ibid., 67.

50 Ibid.

${ }^{51}$ Feinberg, 1995, op. cit., 209.

${ }^{52}$ A. Gutmann, "The Challenge of Multiculturalism in Political Ethics," Philosophy And Public Affairs, 22(3), 1993, 179.

${ }^{53}$ Crittenden, op. cit., 47.

${ }^{54}$ Kymlicka, op. cit.

55 Ibid., 13.

${ }^{56}$ Ibid., 203.

${ }^{57}$ D. Lenihan. "Liberalism and the Problem of Cultural Membership: A Critical Study of Kymlicka," Canadian Journal of Law and Jurisprudence, 4(2), 1991, 403.

${ }^{58}$ Ibid., 404.

${ }^{59}$ Lenihan, op. cit., 419. 